This Section of Epidemiology and Psychiatric Sciences appears in each issue of the Journal to stress the relevance of epidemiology for behavioural neurosciences, reporting the results of studies that explore the use of an epidemiological approach to provide a better understanding of the neural basis of major psychiatric disorders and, in turn, the utilisation of the behavioural neurosciences for promoting innovative epidemiological research.

The ultimate aim is to help the translation of most relevant research findings into every-day clinical practice. These contributions are written in house by the journal's editorial team or commissioned by the Section Editor (no more than 1000 words, short unstructured abstract, four key-words, one Table or Figure and up to ten references).

Paolo Brambilla, Section Editor

\title{
Discordant twins as a tool to unravel the aetiology of bipolar disorder
}

\author{
C. Fagnani ${ }^{1 *}$, M. Bellani ${ }^{2}$, J. C. Soares ${ }^{3}$, M. A. Stazi ${ }^{1}$ and P. Brambilla ${ }^{3,4}$ \\ ${ }^{1}$ Genetic Epidemiology Unit, National Centre of Epidemiology, Surveillance and Health Promotion, Italian National Institute of Health, Rome, Italy \\ ${ }^{2}$ Department of Public Health and Community Medicine, Section of Psychiatry and Clinical Psychology, Inter-University Centre for Behavioural \\ Neurosciences (ICBN), University of Verona, Verona, Italy \\ ${ }^{3}$ Department of Psychiatry and Behavioral Sciences, UT Houston Medical School, Houston, TX, USA \\ ${ }^{4}$ DISM, InterUniversity Center for Behavioural Neurosciences (ICBN), University of Udine, Udine, Italy
}

This editorial focuses on discordant twins as a valuable epidemiological design for psychiatric aetiological research. First, we summarise the advantages and strengths of this design over the classical matched case-control study. Then, we draw attention to the use of this method in bipolar disorder, revising previous discordant-twin studies. A future greater use of discordant twins is desirable to gain further relevant insights in the aetiology of bipolar disorder.

Received 8 January 2014; Revised 9 January 2014; Accepted 14 January 2014; First published online 11 February 2014

Key words: Aetiology, bipolar disorder, discordant, twins.

Classical twin studies aim to separate the contributions of genetic predisposition ('nature') and environmental exposures ('nurture') to the expression of human complex traits. These studies compare trait similarity (i.e., concordance rate or correlation) of monozygotic (MZ) twins (genetically identical) with that of dizygotic (DZ) twins (who share $50 \%$ of their genes): a higher similarity in MZ compared with DZ twins suggests genetic effects on the trait, assuming that environmental factors are shared within twin pairs to the same extent regardless of zygosity ('Equal Environments

* Address for correspondence: Dr C. Fagnani, Genetic Epidemiology Unit, National Centre of Epidemiology, Surveillance and Health Promotion, Italian National Institute of Health, Viale Regina Elena 299, 00161 Rome, Italy.

(Email: corrado.fagnani@iss.it)
Assumption') (Boomsma et al. 2002). Results of classical twin studies proved to be useful in encouraging subsequent efforts to identify the specific gene variants and environmental determinants aetiologically involved in an extraordinary variety of phenotypes.

Aetiological research often uses the matched casecontrol design, where subjects with ('cases') and without ('controls') a given condition are made similar for a number of characteristics ('confounders'), and are compared with respect to the prevalence of an exposure factor. A problem with this design is that cases and controls can only be matched on measured variables (e.g., age, gender, education, etc.), while there may be unmeasured variables (e.g., genetic background, intrauterine or early postnatal environmental exposures, etc.) which may contribute to the observed differences between the two groups. Apart from the 
randomised experiment which is not always feasible when studying humans, one of the best observational approaches to handle this problem is the 'discordanttwin design'. This method uses, as case-control dyads, twin pairs where one twin carries the targeted condition and the co-twin does not. In this way, matching is obtained for age, a key factor in several traits, and can be easily achieved for gender, by considering MZ pairs or same-gender DZ pairs. More importantly, cases and controls are automatically matched also for genotype (totally for $\mathrm{MZ}$ pairs, partially for $\mathrm{DZ}$ pairs), as well as for in-utero exposures and family background. Within such a scenario, the main challenges to causal inference in observational research are neutralised (McGue et al. 2010).

When the condition of interest is a disease, the discordant-twin design compares affected twins with healthy co-twins, and allows the identification of specific aetiological factors. Furthermore, the comparison with an external control group of healthy twins makes it possible to assess if a given trait (e.g., a biological marker) is related to the genetic vulnerability to develop the disease ('endophenotype'). Over the years, the design has been applied to various psychiatric diseases, mainly using MZ twins. In this editorial, we briefly revise some discordant-twin studies that focused on bipolar disorder (BD), coming across different domains, from neuropsychology, to neuroendocrinology, to neuroimaging, up to epigenetics and proteomics.

BD is a severe mental illness characterised by recurrent episodes of mania and depression, which affects approximately $1 \%$ of the population (Merikangas et al. 2011). Classical twin studies indicated a substantial genetic influence on BD liability, with environmental factors also playing a non-negligible role (Edvardsen et al. 2008). Accordingly, both genetic and non-genetic factors were targeted by aetiological research, including investigations on $\mathrm{BD}$ discordant twins.

In a small study on cognitive performance, Gourovitch et al. (1999) found that MZ twins with BD were impaired on measures of visuospatial functioning and verbal memory, as compared with the unaffected co-twins. This suggested that some neuropsychological deficits may be consistent features of $\mathrm{BD}$, related to disease itself.

A major body of research on BD regards the evaluation of candidate endophenotypes, which increase the power of genetic analysis, and also help in reshaping the classical nosological systems and diagnostic categories. Vonk et al. (2007) investigated autoimmune thyroiditis with raised levels of thyroperoxidase antibodies (TPO-Abs) as a biological marker for the transmission of the bipolar genotype, by considering bipolar and healthy control twin pairs. Results showed significantly increased mean TPO-Abs levels in discordant versus healthy twin pairs, but no difference between bipolar patients and their non-bipolar co-twins, suggesting that autoimmune thyroiditis, with TPO-Abs as marker, is a possible BD endophenotype.

Although callosal volume reduction has been observed in BD patients, it is still unclear whether this deficit reflects genetic vulnerability to the illness. To shed light on this issue, Bearden et al. (2011) mapped corpus callosum morphology with MRI techniques on proband $\mathrm{BD}$ twins, their non-BD co-twins and demographically matched control twins. The observation that probands, but not their co-twins, had significant callosal thinning and area reduction (most pronounced in the genu and splenium) relative to healthy twins was consistent with a disease-related deficit, rather than with a genetic reflection of $\mathrm{BD}$ vulnerability.

In recent years, research started to focus on the potential role of epigenetic factors in the aetiology of psychiatric diseases, and BD is no exception. Epigenetic mechanisms affect gene expression mainly through DNA methylation, without involving the genomic DNA sequence. In this context, diseasediscordant $\mathrm{MZ}$ twins represent the ideal design because they allow one to explore epigenomic variation independently of genomic sequence variation. Dempster et al. (2011) were the first to perform a systematic genome-wide analysis of methylation differences between $\mathrm{MZ}$ twins discordant for $\mathrm{BD}$ or schizophrenia. They found considerable differences in DNA methylation between affected and unaffected twins, many of them located in the vicinity of genes previously implicated in psychosis, such as GPR24 and CTNNA2 in BD. These data support epigenetic alterations as relevant in BD and schizophrenia aetiology.

The latest advances in proteomics, combined with the $\mathrm{MZ}$ discordant-twin design, gave additional input to biomarkers identification for BD. The first such study is that of Kazuno et al. (2013), who performed proteomic analysis of lymphoblastoid cells derived from one single pair of BD discordant twins. Their results indicate phosphoglycerate mutase 1 (PGAM1), involved in glycolysis, as a new candidate BD biomarker.

In conclusion, the discordant-twin design is a valuable tool for aetiological research. A future greater use of this design in the psychiatric field is desirable, to gain further relevant insights in the aetiology of major psychoses, particularly BD. The increasing potential of twin registries worldwide (Hur \& Craig, 2012) will facilitate the identification of discordant twin pairs, encouraging the application of such a unique approach. 
Table 1. Published discordant-twin studies on bipolar disorder

\begin{tabular}{|c|c|c|c|c|c|}
\hline Study & Country & $\begin{array}{l}\text { BD } \\
\text { Diagnosis }\end{array}$ & Associated phenotype & Twin sample & $\begin{array}{l}\text { Control } \\
\text { sample }\end{array}$ \\
\hline $\begin{array}{l}\text { Gourovitch } \\
\text { et al. (1999) }\end{array}$ & USA & DSM-III-R & $\begin{array}{l}\text { Neuropsychological performance } \\
\text { (intelligence, attention, } \\
\text { visuospatial skills, language, } \\
\text { learning and memory, abstract } \\
\text { problem solving) }\end{array}$ & $\begin{array}{l}7 \mathrm{MZ} \text { pairs discordant for } \\
\text { BD; mean age: } 32.7 \\
\text { years; mean age of BD } \\
\text { onset: } 25.3 \text { years }\end{array}$ & $\begin{array}{l}7 \mathrm{MZ} \text { normal } \\
\text { pairs; mean } \\
\text { age: } 28.9 \\
\text { years }\end{array}$ \\
\hline $\begin{array}{l}\text { Vonk et al. } \\
\qquad(2007)\end{array}$ & $\begin{array}{l}\text { The } \\
\text { Netherlands }\end{array}$ & DSM-IV & $\begin{array}{l}\text { Autoimmune thyroiditis } \\
\text { (TPO-Abs) }\end{array}$ & $\begin{array}{l}51 \text { BD pairs ( } 22 \mathrm{MZ}, 29 \\
\text { DZ); mean age: } 41.3 \\
\text { years; mean age of } \mathrm{BD} \\
\text { onset: } 28.6 \text { years }\end{array}$ & $\begin{array}{l}35 \text { control } \\
\text { pairs (19 } \\
\text { MZ, 16 DZ); } \\
\text { mean age: } \\
41.2 \text { years }\end{array}$ \\
\hline $\begin{array}{l}\text { Bearden et al. } \\
\text { (2011) }\end{array}$ & Finland & DSM-IV & $\begin{array}{l}\text { Corpus callosum morphology } \\
\text { (callosal thickness and areas) }\end{array}$ & $\begin{array}{l}\text { (i) } 21 \mathrm{BD} \text { twins ( } 4 \mathrm{MZ}, 17 \\
\text { DZ); mean age: } 44.4 \\
\text { years } \\
\text { (ii) } 19 \text { non-BD co-twins ( } 2 \\
\mathrm{MZ}, 17 \mathrm{DZ}) \text {; mean age: } \\
45.1 \text { years }\end{array}$ & $\begin{array}{l}34 \text { twins }(8 \\
\text { MZ, 26 DZ); } \\
\text { mean age: } \\
46.2 \text { years }\end{array}$ \\
\hline $\begin{array}{l}\text { Dempster } \\
\text { et al. }(2011)\end{array}$ & UK & DSM-IV & Genome-wide DNA methylation & $\begin{array}{l}22 \mathrm{MZ} \text { pairs discordant for } \\
\text { BD or schizophrenia; } \\
\text { mean age of BD onset in } \\
\text { BD-discordant pairs: } \\
21.7 \text { years }\end{array}$ & \\
\hline $\begin{array}{l}\text { Kazuno et al. } \\
\text { (2013) }\end{array}$ & Japan & DSM-IV & $\begin{array}{l}\text { Protein expression in } \\
\text { lymphoblastoid cells }\end{array}$ & $\begin{array}{l}1 \mathrm{MZ} \text { pair discordant for } \\
\text { BD; age: } 42 \text { years }\end{array}$ & \\
\hline
\end{tabular}

$\mathrm{BD}$, bipolar disorder; MZ, monozygotic; DZ, dizygotic.

\section{Financial Support}

This work was partially supported by grants from the Italian Ministry of Health (grant no. GR-2010-2316745 to P.B and grant no.GR-2010-2319022 to M.B) and by the BIAL Foundation (Fellowship no. 262/12 to P.B.).

\section{Conflict of Interest}

None.

\section{Ethical Standards}

The authors assert that all procedures contributing to this work comply with the ethical standards of the relevant national and institutional committees on human experimentation and with the Helsinki Declaration of 1975, as revised in 2008.

\section{References}

Bearden CE, van Erp TG, Dutton RA, Boyle C, Madsen S, Luders E, Kieseppa T, Tuulio-Henriksson A, Huttunen M, Partonen T, Kaprio J, Lönnqvist J, Thompson PM, Cannon TD (2011). Mapping corpus callosum morphology in twin pairs discordant for bipolar disorder. Cerebral Cortex 21, 2415-2424.

Boomsma D, Busjahn A, Peltonen L (2002). Classical twin studies and beyond. Nature Review Genetics 3, 872-882.

Dempster EL, Pidsley R, Schalkwyk LC, Owens S, Georgiades A, Kane F, Kalidindi S, Picchioni M, Kravariti E, Toulopoulou T, Murray RM, Mill J (2011).

Disease-associated epigenetic changes in monozygotic twins discordant for schizophrenia and bipolar disorder. Human Molecular Genetics 20, 4786-4796.

Edvardsen J, Torgersen S, Røysamb E, Lygren S, Skre I, Onstad S, Oien PA (2008). Heritability of bipolar spectrum disorders. Unity or heterogeneity? Journal of Affective Disorders 106, 229-240.

Gourovitch ML, Torrey EF, Gold JM, Randolph C, Weinberger DR, Goldberg TE (1999). Neuropsychological performance of monozygotic twins discordant for bipolar disorder. Biological Psychiatry 45, 639-646.

Hur YM, Craig JM (2013). Twin registries worldwide: an important resource for scientific research. Twin Research and Human Genetics 16, 1-12.

Kazuno AA, Ohtawa K, Otsuki K, Usui M, Sugawara H, Okazaki Y, Kato T (2013). Proteomic analysis of lymphoblastoid cells derived from monozygotic twins discordant for bipolar disorder: a preliminary study. PLoS One 8, e53855. 
McGue M, Osler M, Christensen K (2010). Causal inference and observational research: the utility of twins. Perspectives on Psychological Science 5, 546-556.

Merikangas KR, Jin R, He JP, Kessler RC, Lee S, Sampson NA, Viana MC, Andrade LH, Hu C, Karam EG, Ladea M, Medina-Mora ME, Ono Y, Posada-Villa J, Sagar R, Wells JE, Zarkov Z (2011). Prevalence and correlates of bipolar spectrum disorder in the world mental health survey initiative. Archives of General Psychiatry 68, 241-251.

Vonk R, van der Schot AC, Kahn RS, Nolen WA, Drexhage HA (2007). Is autoimmune thyroiditis part of the genetic vulnerability (or an endophenotype) for bipolar disorder? Biological Psychiatry 62, 135-140. 